\title{
Editorial
}

\section{E-Government Rankings for 2012 Stress Importance of Institutional Linkages}

The 2012 United Nations e-Government Rankings of its 193 member countries places heavy emphasis on improving online service delivery, seen as key to enhancing public sector efficiencies and streamline governance systems to support sustainable development. The Waseda University e-Government rankings of 55 countries focus on 7 key indicators that determine advancements in delivery of public services. These indicators have a broad scope measuring network preparedness and management optimization, to national portals, government CIOs, and e-Government promotion. The goals and priorities outlined are clearly complementary.

It is the conclusion of the two surveys that, in the words of the UN, "institutional linkages between and among the tiered government structures in bid to create synergy for inclusive sustainable development." To accomplish this will indeed advance the transformation of governments now recognized as vital to economic and social development.
Korea was ranked No 1 by both organizations which is an outstanding achievement. Korea mapped a Smart e-Government Plan in 2011 that moves beyond technical and operation advances in e-Government and has launched an e-Government Solutions offered commercially to governments and others around the world.

As the UN survey documents, the leading countries in e-Government remain almost exclusively highly advanced economies. However, a growing number of lesser developed countries are seizing opportunities improve infrastructures and introduce e-Government services. This is an important positive trend.

Russell Pipe, Editor in Chief 